\title{
Polypyrrole Film Doped with Corrosion-Inhibitors Electropolymerized on AA 1100
}

\author{
Viviane Dalmoro ${ }^{a}$, Suelen Cedron ${ }^{b}$, Denise Schermann Azambuja ${ }^{b}$, Kátia Regina Lemos Castagno ${ }^{c *}$ (1) \\ ${ }^{a}$ Departamento de Educação, Pesquisa e Extensão, Instituto Federal Sul-rio-grandense, Camaquã, RS, Brasil. \\ 'Instituto de Química, Universidade Federal do Rio Grande do Sul, Porto Alegre, RS, Brasil. \\ 'Departamento de Graduação e Pós- Graduação, Instituto Federal Sul-rio-grandense, Pelotas, RS, Brasil.
}

Received: December 21, 2018; Revised: July 06, 2019; Accepted: July 17, 2019

Polypyrrole films doped with dodecylbenzenesulfonate (PPy/DBS) and with oxy-anions tungstate (PPy/DBS/TUN) and vanadate (PPy/DBS/VAN) were potentiostatically electropolymerized on aluminum alloy 1100 (AA1100). The corrosion protection of these films was evaluated by the variation of the corrosion potential $\left(\mathrm{E}_{\mathrm{CORR}}\right)$ with the immersion time and by electrochemical impedance spectroscopy (EIS) measurements in $0.05 \mathrm{~mol} \mathrm{~L}^{-1} \mathrm{NaCl}$ and $0.05 \mathrm{~mol} \mathrm{~L}^{-1} \mathrm{HCl}$ solutions. The EIS measurements suggest that the tungstate and the vanadate play the role of a dopant and an inhibitor. The results presented here show that PPy/DBS/TUN and PPy/DBS/VANprovide a protective effect against the corrosion of the AA1100. It was shown that the oxyanions' inhibitory action is different depending on the electrolyte $\mathrm{pH}$. In an $\mathrm{HCl}$ solution PPy/DBS/TUN films improve protection against aluminum alloy's corrosion. On the other hand, in a $\mathrm{NaCl}$ solution, PPy/DBS/VAN films and PPy/DBS/TUN films act as inhibitor, the former being more effective.

Keywords: Polymers, corrosion test, electrochemical techniques.

\section{Introduction}

Aluminum and its alloys suffer localized corrosion in aggressive media, such as aqueous solutions containing chlorides, with the passive oxide layer's destruction, forming pits. Aluminum alloys (AA) 1100 are employed in conventional engineering applications in which corrosion resistance is required but strength is relatively unimportant (e.g., architectural, appliance trim and low pressure tubing for carrying chemicals and foodstuffs). However, AA1100 is susceptible to corrosion due to alloying elements such as iron, silicon and copper that form intermetallic compound particles in the alloy ${ }^{1}$.

The various processes employed in industry to mitigate the incidence of corrosion in aluminum alloys include those that use coatings formulated with $\mathrm{Cr}$ (VI) compounds which are extremely toxic and carcinogenic, and require an appropriate treatment prior to final waste disposal. Alternative processes for the aluminum's protection against corrosion have been considered aiming to replace the traditional chromate treatments, such as the silane-based pretreatments ${ }^{2-4}$, conversion coatings using inhibitors ${ }^{5-6}$ and conductive polymers ${ }^{7-13}$.

The conductive polymers (CPs), such as polyaniline, polypyrrole, polythiophene and polyindole, can be used as primer coatings or as components blended with conventional coatings (non-conductive paints) in corrosion control. A CP coating acts as an oxidant to the substrate metals, forming a stable oxide film, i.e., a passivation film is formed on the metal. The CP coatings have been widely studied because of their relatively high environmental stability, non-toxic properties, easily adjustable conductive oxidation states, and simple and economic production routes ${ }^{14}$.
DeBerry $^{15}$, Ahmad and MacDiarmid ${ }^{16}$ were pioneers in using $\mathrm{CP}$ as an electroactive protective coating against the corrosion of active/passive metals. However, the corrosion protection mechanism associated with CPs has not yet been fully understood. The most effective protection against corrosion occurs with CPs in the doped and oxidized state, which corresponds to a conductive form of polymer ${ }^{17}$.

Kendig et al. ${ }^{18}$ has provided evidence that anionic inhibitors for the oxygen reduction reaction (ORR), when used as dopants of conducting polyaniline(PANI) films, decrease the AA2024-T3 substrate's corrosion at a scribe, due to dopant's release, that acts as an inhibitor. According to the authors, when the coating is fractured, the oxidized PANI film containing inhibiting anions (the dopant) becomes a cathode and the metal scratch as an anode. The anodic corrosion reaction drives the film's reduction in the doped acidified state or the oxygen's reduction at the film's surface, or both. These reduction processes cause the release of the inhibiting anions, thus these inhibitors stop the corrosion at the $\operatorname{scratch}^{19}$.

We demonstrated that the coating of polypyrrole films doped with oxalic acid and tungstate (PPy/OXA/W), on AA1100, can provide protection against corrosion in chloride solution $^{20}$. The improved corrosion resistance observed can be ascribed to the polypyrrole film's partial reduction and the consequent tungstate anions'release from the polymer matrix. Therefore, the repair of defects in the metallic substrate and within the pits is due to the tungstate anion's adsorption, leading to a more stable oxide passivation layer. Under these conditions, the tungstate anion acts as a dopant and inhibitor. 
It has been reported that polypyrrole (PPy) films electrosynthesized in the presence of highly amphiphilic anionic surfactants present good mechanical properties and a high electrical conductivity due to the high degree of polymeric chain ordering attained with these dopants ${ }^{21-23}$. In previous studies performed by our research group, polypyrrole/dodecylbenzenesulfonate (PPy/DBS) films were electropolymerized on a platinum surface to determine their chemical and physical characteristics and on an AA1100 alloy to evaluate their performance in terms of corrosion protection in chloride solutions ${ }^{24}$. The PPy/DBS coatings' potentiodynamic polarization curves produced on the AA1100 surface, in $0.05 \mathrm{~mol} \mathrm{~L}^{-1} \mathrm{NaCl}$ and $0.05 \mathrm{~mol} \mathrm{~L}^{-1} \mathrm{HCl}$, resulted in a shift in the corrosion potential to more positive values and a decrease in the corrosion current density, indicating an improvement in the corrosion resistance.

The aim of this study was to investigate dodecylbenzenesulfonate anions' effect with the oxy-anions tungstate and vanadate in the electrochemical deposition of PPy, on AA1100, to obtain a protective film against corrosion. The corrosion protection of these films was evaluated through the corrosion potential's $\left(\mathrm{E}_{\mathrm{CORR}}\right)$ variation with the immersion time and by electrochemical impedance spectroscopy (EIS) tests in $0.05 \mathrm{~mol} \mathrm{~L}^{-1} \mathrm{NaCl}$ and $0.05 \mathrm{~mol} \mathrm{~L}^{-1} \mathrm{HCl}$ solutions. Simultaneously, the coated electrodes were characterized by scanning electron microscopy (SEM) and energy dispersive $\mathrm{x}$-ray spectroscopy (EDX).

\section{Experimental Methods}

Prior to use, Pyrrole (Aldrich, 99\%) was vacuum-distilled and stocked at $4{ }^{\circ} \mathrm{C}$.

The experiments were performed in the presence of dissolved oxygen and at room temperature $\left(24^{\circ} \mathrm{C}\right)$. A 1.0 x $1.0 \mathrm{~cm} \mathrm{AA1100} \mathrm{sheet} \mathrm{[99 \% w/w} \mathrm{Al,}(1.00+\mathrm{Fe}) \% \mathrm{w} / \mathrm{w}$ $\mathrm{Si}, 0.05-0.2 \% \mathrm{w} / \mathrm{w} \mathrm{Cu}, 0.05 \% \mathrm{w} / \mathrm{w} \mathrm{Mn}, 0.1 \% \mathrm{w} / \mathrm{w} \mathrm{Zn}$, $0.05 \% \mathrm{w} / \mathrm{w} \mathrm{C}]$, a Pt gauze and saturated calomel electrode (SCE) were employed as the working, counter and reference electrodes, respectively.

The working electrode was pretreated by galvanostatic activation for $120 \mathrm{~s}$ at $27 \mathrm{~mA} \mathrm{~cm}^{-2}$ in a mixture of $0.1 \mathrm{~mol} \mathrm{~L}^{-1}$ $\mathrm{HNO}_{3}\left(\right.$ Synth, $65 \%$ ) and $0.1 \mathrm{~mol} \mathrm{~L}^{-1}$ Pyrrole. This procedure was carried out based on the work of Hülser and $\mathrm{Beck}^{25}$ who reported that this method provides a cohesive and adherent layer of deposited PPy. Following this pretreatment, the electrode was washed with deionized water and transferred to the electrochemical cell.

As a typical procedure, $0.1 \mathrm{~mol} \mathrm{~L}^{-1}$ sodium dodecylbenzenesulfonate (Acros Organics, 88\%), 0.1 mol L-1 oxalic acid (Alphatec, 99.5\%) and $0.05 \mathrm{~mol} \mathrm{~L}^{-1}$ sodium tungstate (Synth, 99\%) or $0.05 \mathrm{~mol} \mathrm{~L}^{-1}$ sodium metavanadate (Sigma-Aidrich, 99.9\%) were dissolved under magnetic stirring and $0.4 \mathrm{~mol} \mathrm{~L}^{-1}$ pyrrole was added afterwards. Oxalic acid was used to adjust the $\mathrm{pH}$ because it provides to obtain well-adhering homogeneous PPy films ${ }^{20}$.
Then, the electropolymerization was performed potentiostatically at $1.0 \mathrm{~V}$ until $1.0 \mathrm{C}$. The thickness of the PPy films, was calculated according to Schirmeisen and $\mathrm{Beck}^{26}$, from the equation, $\mathrm{d}=\mathrm{Q} \times \mathrm{m}_{\mathrm{e}} \times \mathrm{\rho}^{-1}$, where: $\mathrm{Q}=$ charge per unit area of substrate polymerization $\left(\mathrm{C} \mathrm{cm}^{-2}\right)$; $\rho=$ polypyrrole density $\left(1.5 \mathrm{~g} \mathrm{~cm}^{-3}\right)$; and me $=$ electrochemical equivalent $\left(\mathrm{g} \mathrm{C}^{-1}\right)$. The PPy films electrosynthesized potentiostatically at $1.0 \mathrm{~V}$ until 1.0

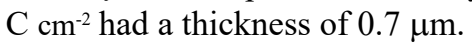

Subsequently, the films were rinsed thoroughly with deionized water and left in the presence of dissolved oxygen at room temperature before performing the electrochemical measurements.

The electrochemical measurements were performed using an AUTOLAB PGSTAT 30/FRA 2 system open to the air, at room temperature $\left(24^{\circ} \mathrm{C}\right)$. The films' corrosion protection produced on the AA1100 surface was evaluated by the corrosion potential $\left(\mathrm{E}_{\mathrm{CORR}}\right)$ and by electrochemical impedance spectroscopy (EIS) measurements in $0.05 \mathrm{~mol} \mathrm{~L}^{-1}$ $\mathrm{NaCl}(\mathrm{pH}=7.0)$ and $0.05 \mathrm{~mol} \mathrm{~L}^{-1} \mathrm{HCl}(\mathrm{pH}=1,3)$ solutions. The EIS tests were performed at the open-circuit potential (OCP) in the $100 \mathrm{kHz}-50 \mathrm{mHz}$ frequency range, and the sinusoidal voltage amplitude was $10 \mathrm{mV}$. For all experiments at least three replicates were run to ensure reproducibility of experimental data. The film's surface was examined by an scanning electron microscopy (SEM) and Energy dispersive X-ray spectroscopy (EDS) using a JEOLJSM 5800 microscope at $20 \mathrm{kV}$.

\section{Results and Discussion}

\subsection{Electrosynthesis}

Potentiostatic electrodeposition was chosen as the electrosynthesis method since it allows easy control of the potential ${ }^{27}$. In addition, the films obtained by this method are homogeneous and have a good reproducibility ${ }^{18}$.

The transients shown in Figure 1 presents the characteristic behavior of the conducting polymer films' growth, as reported in previous studies ${ }^{27-29}$, and it depends on the applied potential, the concentration of the monomer and the nature of the species present in solution. As can be seen in Figure 1, the I-t transients obtained for the PPy/DBS films achieved the second period in a very short time $(80 \mathrm{~s})$ with the maximum anodic current values of $6.7 \times 10^{-3} \mathrm{~A} \mathrm{~cm}^{-2}$, suggesting that the electropolymerization rate of this film was faster than the other films. This behavior can be attributed to the sulfonate group, that promotes the simultaneous formation of aluminum oxide and PPy and the pores then become excellent hydrophobic sites for pyrrole electropolymerization ${ }^{23}$. On the other hand, the presence of vanadate and tungstate species has an adverse effect on the PPy electrosynthesis, since it decreases the anode current value, thus the total charge of $1.0 \mathrm{C}$ is achieved after long periods. 


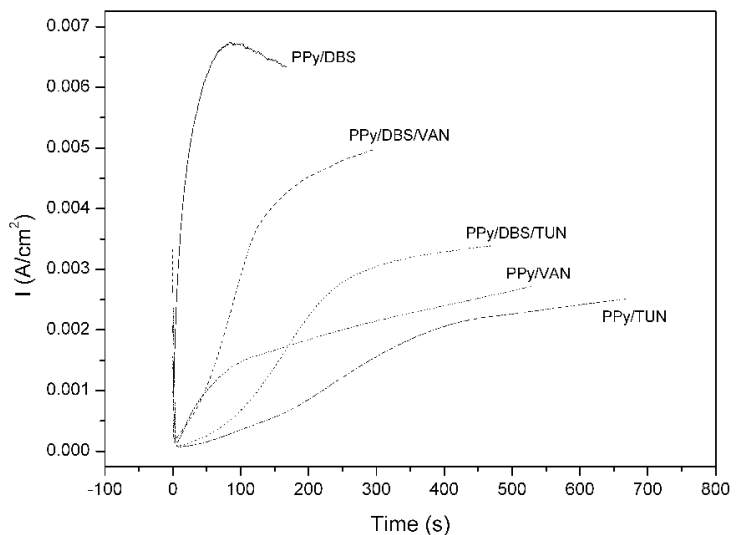

Figure 1. I-t transients obtained for the electrosynthesis of PPy on AA 1100 at $1.0 \mathrm{~V}$ in $0.4 \mathrm{~mol} \mathrm{~L}^{-1}$ pyrrole with: $0.05 \mathrm{~mol} \mathrm{~L}^{-1} \mathrm{Na}_{2} \mathrm{VO}_{4}$ (PPy/VAN); $0.05 \mathrm{~mol} \mathrm{~L}^{-1} \mathrm{Na}_{2} \mathrm{WO}_{4}$ ( PPy/ TUN); $0.1 \mathrm{~mol} \mathrm{~L}^{-1} \mathrm{SDBS}^{2}$ (PPy/DBS) and $0.05 \mathrm{~mol} \mathrm{~L}^{-1} \mathrm{Na}_{2} \mathrm{VO}_{4}(\mathrm{PPy} / \mathrm{DBS} / \mathrm{VAN})$ or $0.05 \mathrm{~mol}$ $\mathrm{L}^{-1} \mathrm{Na}_{2} \mathrm{WO}_{4}(\mathrm{PPy} / \mathrm{DBS} / \mathrm{TUN})$.

We have previously reported that the PPy electropolymerization is hindered in $\mathrm{WO}_{4}^{2-}$-solutions ${ }^{20}$ due to nucleophilic character of the tungstate anions, which can attack the radical cations and inhibit the electropolymerization process and, consequently, the film formation and the growth.
The vanadium's aqueous chemistry is complex due to the several possible oxidation states and the different acidic or basic behaviors associated with each of these states. At low $\mathrm{pH}(1.0<\mathrm{pH}<2.2)$ the metavanadate is protonated and polymerizes, forming decavanadate $\left[\mathrm{V}_{10} \mathrm{O}_{28}{ }^{6-}\right]^{30}$. The anodic current values observed for the PPy electrosynthesis in the presence of vanadate species suggest that these species compete with the dodecylbenzenesulfonate anion in polypyrrole doping, making the electropolymerization process difficult.

\subsection{Characterization of PPy filmsby scanning electron microscopy (SEM) and Energy dispersive $X$-ray spectroscopy $(E D X)$}

The SEM micrographs and the results for the EDX analysis of the PPy/DBS PPy/DBS/VAN and PPy/DBS/TUN electrodeposited on the AA1100 substrate are depict in Figure 2.

The films have a globular structure, with the aggregates formation of and a uniform surface morphology, known as a "cauliflower" structure, often found in the case of PPy films ${ }^{27}$. However, the "cauliflower" structure seems to be underdeveloped, or less bulky, for films doped with anion inhibitors (Figs. 2B and 2C). The EDX analysis shown in Table 1 confirmed the presence of the dopants in the films.
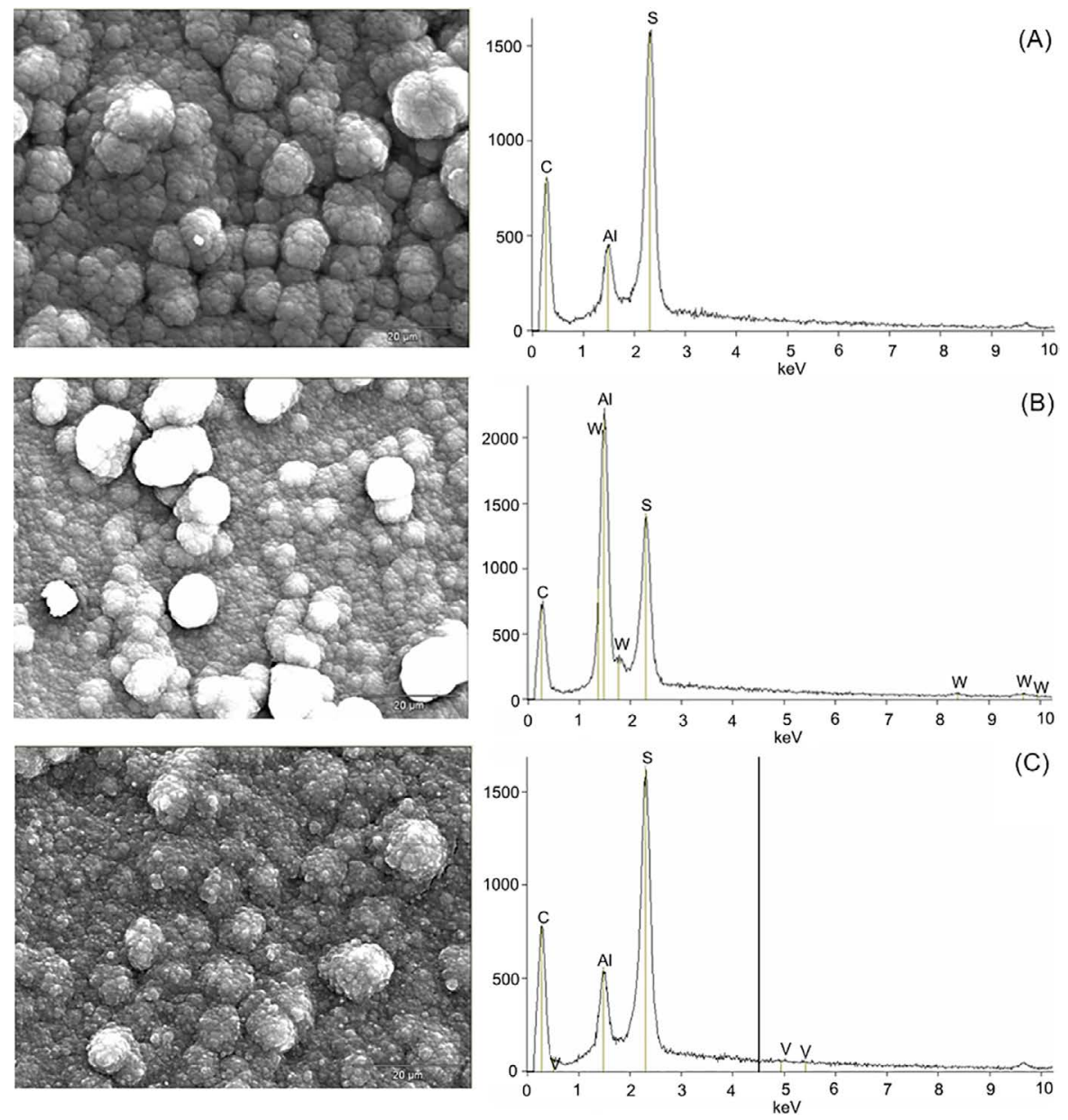

Figure 2. SEM and EDS analysis of the (A) PPy/DBS; (B) PPy/DBS/TUN; (C) PPy/DBS/VAN films. 
Table 1. EDS analysis for the PPy/DBS PPy/DBS/VAN and $\mathrm{PPy} / \mathrm{DBS} / \mathrm{TUN}$ electrodeposited on the AA 1100 substrate

\begin{tabular}{lccccc}
\hline \multirow{2}{*}{ Films } & \multicolumn{5}{c}{ Elements $(\% \mathrm{w} / \mathrm{w})$} \\
\cline { 2 - 6 } & $\mathrm{C}$ & $\mathrm{Al}$ & $\mathrm{S}$ & $\mathrm{W}$ & $\mathrm{V}$ \\
\hline PPy/DBS & 87.40 & 1.74 & 10.86 & - & - \\
PPy/DBS/TUN & 83.70 & 8.25 & 6.45 & 1.60 & - \\
PPy/DBS/VAN & 87.18 & 2.32 & 10.41 & - & 0.09 \\
\hline
\end{tabular}

The results in Table 1 show high sulfur content for all films, which suggests a predominance of the DBS- anion doping of the polymer. For the PPy/DBS/TUN film the EDX analysis depicts a lower sulfur content and higher content of aluminum than the other films. This result suggests that the tungstate anion $\left(\mathrm{WO}_{4}^{2-}\right)$ interferes with the electropolymerization process and, consequently, film formation, growth, composition and morphology.

EDS analysis for the PPy/DBS/VAN film shows that vanadium is present in low concentration. In the low $\mathrm{pH}$ condition, in which the synthesis of the films was performed, decavanadate anion $\left[\mathrm{V}_{10} \mathrm{O}_{28}{ }^{6-}\right]$ is present. The dimensions of this anion are $5 \times 7.7 \times 8.3 \AA$, that is the shape of an elongated barrel $^{31}$. The EDS analysis result for the PPy/DBS/VAN film suggests that decavanadate anion finds spatial difficulties to incorporate the polypyrrole chain and act as a dopant.

\subsection{Corrosion protection performance}

The protection against corrosion of PPy films onto alloys was evaluated by the variation of the corrosion potential $\left(\mathrm{E}_{\mathrm{CORR}}\right)$ with the immersion timein $0.05 \mathrm{~mol} \mathrm{~L}^{-1} \mathrm{NaCl}$ and $0.05 \mathrm{~mol} \mathrm{~L}^{-1} \mathrm{HCl}$ solutions (Figure 3).

The curves shown in Figure 3(A) and 3(B) show that the corrosion potential drops to approximately 2000 seconds of immersion, from which the potential reaches steady state. This potential drop behavior may be related to the penetration of the electrolyte into the pores of the coating and its arrival at the metal surface, shifting the potential to more negative values.

(A)

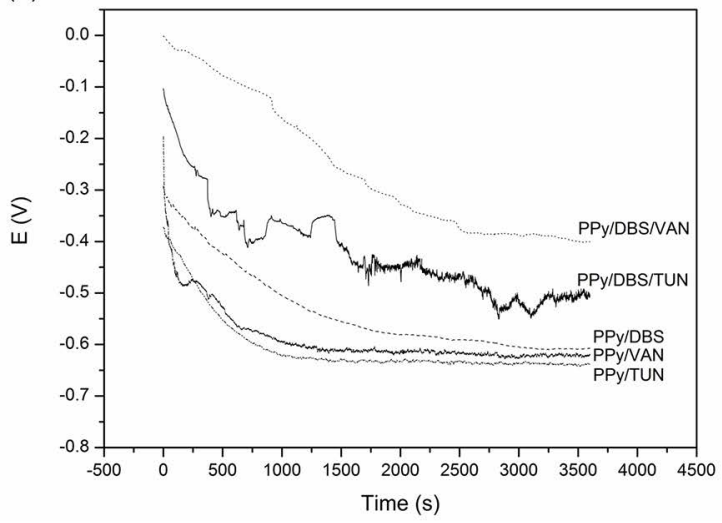

As can be seen in Figure 3(A) and (B), when TUN and VAN anions are added to the PPy/DBS film a potential shift to more positive values is observed in both solutions, suggesting a collaborative effect of these anions in mitigating the corrosion process. However, the performance of films in neutral media (Fig. 3A) is better than in acid media, since the potentials in the first are more positive than in the second (Fig. 3B).

Although the performance of PPy/DBS/TUN and PPy/ DBS/VAN films provides similar protection for the alloy, it is observed that the former offers protection in $\mathrm{HCl}$ solution, while the latter, provides protection in neutral $\mathrm{NaCl}$ solution. The same behavior was found in the EIS measurements.

The corrosion behavior of PPy films on the aluminum alloy, as a function of immersion time was investigated by EIS measurements at open-circuit potential (OCP) in both solutions (Figure 4).

Figure 4(A) shows the Nyquist plots of the AA1100 electrode coated with these films after $1 \mathrm{~h}$ of immersion in $0.05 \mathrm{~mol} \mathrm{~L}^{-1} \mathrm{NaCl}$ solution. The Nyquist diagrams show a depressed capacitive loop within a broad frequency range and a tail at lowest frequencies attributed to a Warburg impedance, which takes into account the effect of mass transport within the pores and coating defects ${ }^{32}$. For the films produced using only DBS and oxy-anions the resistance values obtained are less than the PPy films containing oxy-anion inhibitors and DBS. These features are in accordance with the potentiometric measurements and suggested a synergistic effect between dodecylbenzenesulfonate and tungstate/vanadate compounds in corrosion protection of AA1100.

Figure 4(B) depicts the EIS spectra for the aluminum alloy coated with the five films under investigation in 0.05 mol L ${ }^{-1} \mathrm{HCl}$ solution after $1 \mathrm{~h}$ immersion. The PPy/DBS and PPy/DBS/VAN show a capacitive loop at high frequency and inductive behavior at lowest frequencies. These inductive points have been ascribed to relaxation of adsorbed species at the substrate surface and related to localized corrosion ${ }^{33}$.

(B)

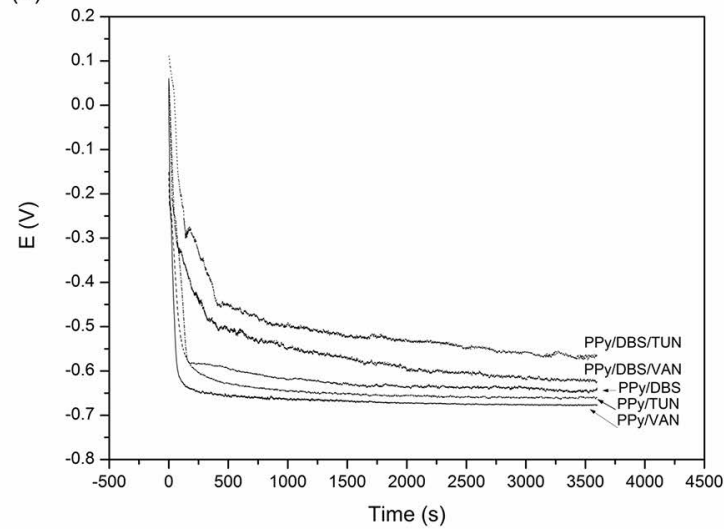

Figure 3. The corrosion potential (ECORR) as a function of the immersion time in (A) $0.05 \mathrm{~mol} \mathrm{~L}^{-1} \mathrm{NaCl}$ and (B) $0.05 \mathrm{~mol} \mathrm{~L}^{-1} \mathrm{HCl}$ solutions of the AA 1100 coated with PPy films. 
For the PPy/DBS and PPy/DBS/VAN films Rp values close to 790 and $350 \Omega \mathrm{cm}^{-2}$ were found, respectively. The PPy/ DBS/TUN film present a different behavior, with a capacitive loop in a broad frequency range followed by a Warburg diffusional tail ${ }^{20,21}$ with an increased $\mathrm{Rp}$ value (around 1.5 $\mathrm{k} \Omega \mathrm{cm}^{-2}$ ). The overall impedance shown at the EIS spectra encompasses the contribution of a different resistance present in the system, including the resistance due to the processes of substrate dissolution, charge transfer resistance during PPy reduction, pore electrolyte resistance and mass transport process resistance.

These results indicate that the oxy-anions tungstate and vanadate play the role of dopant and inhibitor when added to PPy/DBS films. It has been proposed a mechanism of a corrosion protection based on CPs acting as a reservoir of inhibitors has been proposed, and can release them during polymer reduction upon activation by local electrochemical reactions as a corrosion process' consequence ${ }^{20}$. The structural and conformational changes that occur in the polymer matrix are determinant in the CPs' protective characteristics $^{34}$.

The EIS results should be interpreted taking into account the vanadium and tungsten speciation's effect on the aluminum inhibition. Whether vanadate species provide inhibition of aluminum alloys strongly depends on the solution $\mathrm{pH}^{35,36}$.
Reported results showed that inhibition by vanadates occurred mainly in alkaline solutions where tetrahedrally coordinated vanadates, metavanadate and pyrovanadate, were abundant. Inhibition was not observed in solutions where octahedric coordinated decavanadates predominated. At $\mathrm{pH}$ values between 6 and 9 the metavanadates' formation predominates and at acid $\mathrm{pH}$ the vanadium's coordination changes from tetrahedral to octahedral. Despite the predominance of a particular species in a given $\mathrm{pH}$, other species can be present in solution in smaller proportions modifying the overall inhibition.

Similar features are involved in the tungstate's action. Soluble tungsten compounds may include a large amount of polymeric forms, polymerization depending strongly on $\mathrm{pH}$, as the reaction is initiated by protonation ${ }^{37}$. It is well known that polymeric anions are formed in tungstate solutions under acidic conditions. At $\mathrm{pH}$ 2.0, the metatungstate anion $\mathrm{H}_{2} \mathrm{~W}_{12} \mathrm{O}_{40}{ }^{6-}$ is one of the most probable species of polytungstate anion ${ }^{38}$. Polyoxotungstates include tungsten atoms in the highest oxidation state, and, therefore, these compounds can act as corrosion inhibitors. Such considerations can explain the different behaviors against corrosion, obtained in this study for the vanadate and tungstate species.

The variations of the overall impedance for the PPy/DBS, PPy/DBS/VAN and PPy/DBS/TUN electrodeposited on the AA1100 substrate with immersion time in (A) $0.05 \mathrm{~mol} \mathrm{~L}^{-1} \mathrm{NaCl}$ and (B) $0.05 \mathrm{~mol} \mathrm{~L}^{-1} \mathrm{HCl}$ solutions are depicted in Figure 5.

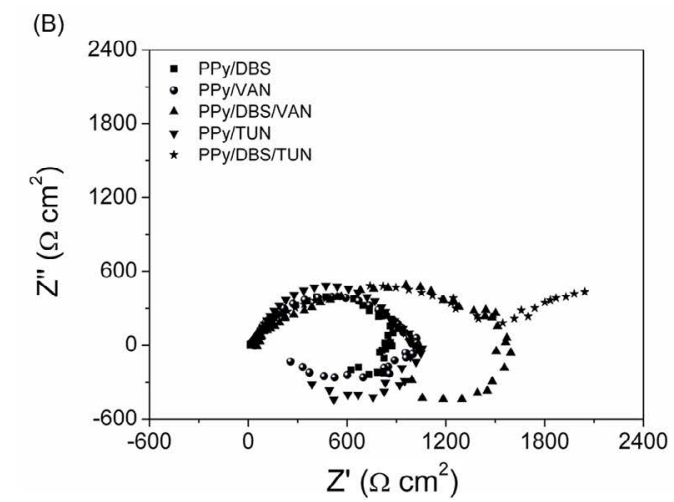

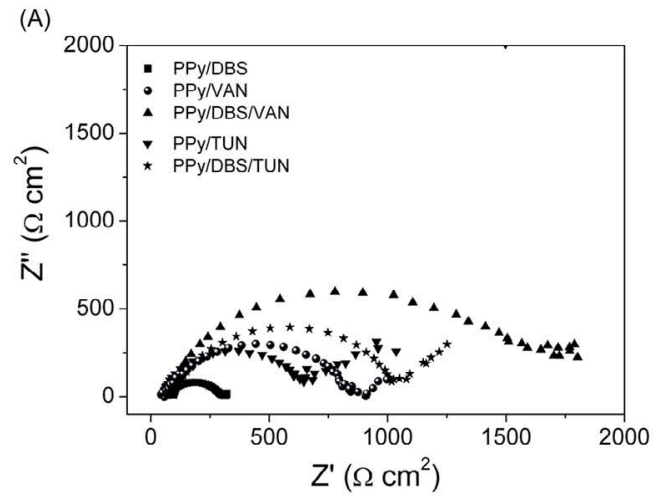

Figure 4. Nyquist plots of the AA 1100 electrode coated with PPy films, after $1 \mathrm{~h}$ of immersion in (A) $0.05 \mathrm{~mol} \mathrm{~L}^{-1}$ $\mathrm{NaCl}$ and (B) $0.05 \mathrm{~mol} \mathrm{~L}^{-1} \mathrm{HCl}$ solutions.

(A)

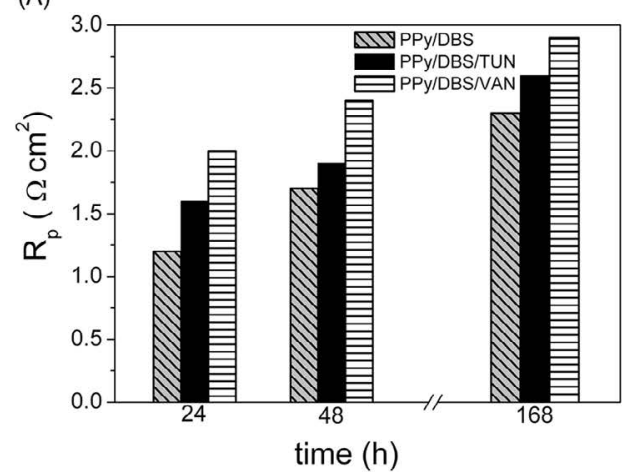

(B)

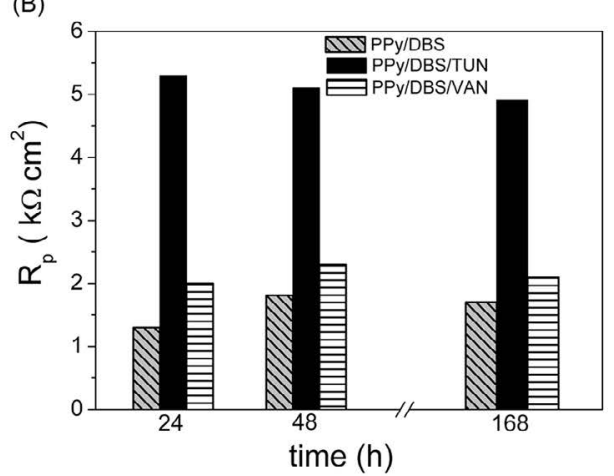

Figure 5. Variations of the overall impedance for the PPy films electrodeposited on the AA1100 substrate with immersion time in (A) $0.05 \mathrm{~mol} \mathrm{~L}^{-1} \mathrm{NaCl}$ and (B) $0.05 \mathrm{~mol} \mathrm{~L}^{-1} \mathrm{HCl}$ solutions. 
The EIS plots at prolonged immersion time, confirming that a synergistic effect was obtained with the incorporation of oxy-anions into the PPy/DBS matrix. It is believed that oxyanions may be released during polymer reduction, adsorbing at the active surface sites and blocking or repairing the pits.

\section{Conclusions}

Modified PPy/DBS films doped with oxy-anions tungstate and vanadate provide a protective effect against the corrosion of the AA1100 alloy. The corrosion potentials are shifted to more positive values with the oxy-anions' addition in the polypyrrole films. The EIS results revealed that the inhibitory action of both oxy-anions is different depending on the electrolyte $\mathrm{pH}$, and in $\mathrm{HCl}$ solution $\mathrm{PPy} / \mathrm{DBS} / \mathrm{TUN}$ film propitiate a greater corrosion protection. On the other hand in the $\mathrm{NaCl}$ solution PPy/DBS/VAN and PPy/DBS/ TUN films act as inhibitor, and the former is more effective. This behavior was explained taking into account the effect of vanadium and tungsten speciation on the aluminum's inhibition. Based on the present results, it was demonstrated that a cooperative effect can be obtained by using PPy/DBS films doped with tungstate or vanadate to produce protective films by selecting either vanadate or tungstate, depending on the electrolyte $\mathrm{pH}$.

\section{Acknowledgements}

The authors gratefully acknowledge the support of this work by CNPq.

\section{References}

1. Ezuber H, El-Houd A, El-Shawesh F. A study on the corrosion behavior of aluminum alloys in seawater. Materials \& Design. 2008;29(4):801-805.

2. Tamborim SM, Maisonnave APZ, Azambuja DS, Englert GE. An electrochemical and superficial assessment of the corrosion behavior of AA 2024-T3 treated with metacryloxypropylmethoxysilane and cerium nitrate. Surface and Coatings Technology. 2008;202(24):5991-6001.

3. Dalmoro V, dos Santos JHZ, Armelin E, Alemán C, Azambuja DS. Phosphonic acid/silica-based films: A potential treatment for corrosion protection. Corrosion Science. 2012;60:173-180.

4. Trueba M, Trasatti SP. Pyrrole-based silane primer for corrosion protection of commercial Al alloys: Part I: Synthesis and spectroscopic characterization. Progress in Organic Coatings. 2009;66(3):254-264.

5. Twite RL, Bierwagen GP. Review of alternatives to chromate for corrosion protection of aluminum aerospace alloys. Progress in Organic Coatings. 1998;33(2):91-100.
6. Ralston KD, Chrisanti S, Young TL, Buchheit RG. Corrosion Inhibition of Aluminum Alloy 2024-T3 by Aqueous Vanadium Species. Journal of The Electrochemical Society. 2008;155(7):C350-C359.

7. Tallman DE, Spinks G, Dominis A, Wallace GG. Electroactive conducting polymers for corrosion control. Journal of Solid State Electrochemistry. 2002;6(2):73-84.

8. Rohwerder M, Michalik A. Conducting polymers for corrosion protection: What makes the difference between failure and success? Electrochimica Acta. 2007;53(3):1300-1313.

9. Gupta G, Birbilis N, Cook AB, Khanna AS. Polyanilinelignosulfonate/epoxy coating for corrosion protection of AA2024-T3. Corrosion Science. 2013;67:256-267.

10. Anicai L, Florea A, Buda M, Visan T. Polypyrrole Films Doped with Phosphomolybdate Anions on Al Surfaces - Formation and Corrosion Protection Characterisation. Zeitschrift für Physikalische Chemie. 2013;227(8):1121-1141.

11. Deyab MA. Corrosion protection of aluminum bipolar plates with polyaniline coating containing carbon nanotubes in acidic medium inside the polymer electrolyte membrane fuel cell. Journal of Power Sources. 2014;268:50-55.

12. $\mathrm{Xu}$ J, Zhang Y, Tang Y, Cang H, Jing W. Comparative Study on the Electrodeposition and Corrosion Resistance of Polypyrrole Doped by Phosphotungstate and Benzalkonium Chloride. Industrial \& Engineering Chemistry Research. 2014;53(48):18473-18480.

13. Yong KC. Enhancing the Corrosion Inhibition Behaviour of Epoxidized Natural RubberPolyaniline Dodecylbenzenesulfonate Blend via the Incorporation of $\mathrm{WO}_{3}$. Polymers and Polymer Composites. 2017;25(2):135-142.

14. Shabani-Nooshabadi M, Ghoreishi SM, Behpour M. Electropolymerized polyaniline coatings on aluminum alloy 3004 and their corrosion protection performance. Electrochimica Acta. 2009;54(27):6989-6995.

15. DeBerry DW. Modification of the Electrochemical and Corrosion Behavior of Stainless Steels with an Electroactive Coating. Journal of The Electrochemical Society. 1985;132(5):1022-1026.

16. Ahmad N, MacDiarmid AG. Inhibition of corrosion of steels using conducting polymers. Bulletin of the American Physical Society. 1987;32:548-555.

17. Khalkhali RA. Electrochemical Synthesis and Characterization of Electroactive Conducting Polypyrrole Polymers. Russian Journal of Electrochemistry. 2005;41(9):950-955.

18. Kendig M, Hon M, Warren L. 'Smart' corrosion inhibiting coatings. Progress in Organic Coatings. 2003;47(3-4):183-189. 
19. Rammelt U, Duc LM, Plieth W. Improvement of protection performance of polypyrrole by dopant anions. Journal of Applied Electrochemistry. 2005;35(12):1225-1230.

20. Castagno KRL, Azambuja DS, Dalmoro V. Polypyrrole electropolimerized on aluminum alloy 1100 doped with oxalate and tungstate anions. Journal of Applied Electrochemistry. 2009;39(1):93-100.

21. De Paoli MA, Peres RCD, Panero S, Scrosati B. Properties of electrochemically synthesized polymer electrodes - X. Study of polypyrrole/ dodecylbenzene sulfonate. Electrochimica Acta. 1992;37(7):1173-1182.

22. Saidman SB, Vela ME. Electropolymerisation of pyrrole onto aluminium from alkaline solutions containing a surfactant. Thin Solid Films. 2005;493(1-2):96-103.

23. Naoi K, Takeda M, Kanno H, Sakakura M, Shimada A. Simultaneous electrochemical formation of $\mathrm{Al}_{2} \mathrm{O}_{3}$ /polypyrrole layers (I): effect of electrolyte anion in formation process. Electrochimica Acta. 2000;45(20):3413-3421.

24. Castagno KRL, Dalmoro V, Azambuja DS. Characterization and corrosion of polypyrrole/sodium dodecylbenzene sulfonate electropolymerised on aluminum alloy 1100. Materials Chemistry and Physics. 2011;130(1-2):721-726.

25. Hülser P, Beck F. Electrodeposition of polypyrrole layers on aluminium from aqueous electrolytes. Journal of Applied Electrochemistry. 1990;20(4):596-605.

26. Schirmeisen M, Beck F. Electrocoating of iron and other metals with polypyrrole. Journal of Applied Electrochemistry. 1989;19(3):401-409.

27. Herrasti P, Díaz L, Ocón P, Ibáñez A, Fatas E. Electrochemical and mechanical properties of polypyrrole coatings on steel. Electrochimica Acta. 2004;49(22-23):3693-3699.

28. Conroy KG, Breslin CB. The electrochemical deposition of polyaniline at pure aluminium: electrochemical activity and corrosion protection properties. Electrochimica Acta. 2003;48(6):721-732.
29. Saidman SB, Bessone JB. Electrochemical preparation and characterisation of polypyrrole on aluminium in aqueous solution. Journal of Electroanalytical Chemistry. 2002;521(1-2):87-94.

30. Iannuzzi M, Young T, Frankel GS. Aluminum Alloy Corrosion Inhibition by Vanadates. Journal of The Electrochemical Society. 2006;153(12):B533-B541.

31. Samart N, Saeger J, Haller KJ, Aureliano M, Crans DC. Interaction of Decavanadate with Interfaces and Biological Model Membrane Systems: Characterization of Soft Oxometalate Systems. Journal of Molecular and Engineering Materials. 2014;2(1):1440007.

32. Walter GW. A review of impedance plot methods used for corrosion performance analysis of painted metals. Corrosion Science. 1986;26(9):681-703.

33. Metikoš-Huković M, Babić R, Grubač Z, Brinć S. Impedance spectroscopic study of aluminium and Al-alloys in acid solution: inhibitory action of nitrogen containing compounds. Journal of Applied Electrochemistry. 1994;24(8):772-778.

34. Rizzi M, Trueba M, Trasatti SP. Polypyrrole films on Al alloys: The role of structural changes on protection performance. Synthetic Metals. 2011;161(1-2):23-31.

35. Iannuzzi M, Frankel GS. Mechanisms of corrosion inhibition of AA2024-T3 by vanadates. Corrosion Science. 2007;49(5):2371-2391.

36. Iannuzzi M, Kovac J, Frankel GS. A study of the mechanisms of corrosion inhibition of AA2024-T3 by vanadates using the split cell technique. Electrochimica Acta. 2007;52(12):4032-4042.

37. Strigul N. Does speciation matter for tungsten ecotoxicology? Ecotoxicology and Environmental Safety. 2010;73(6):1099-1113.

38. Cheng SA, Otero TF. Electrogeneration and electrochemical properties of hybrid materials: polypyrrole doped with polyoxometalates $\mathrm{PW}_{12-\mathrm{x}} \mathrm{Mo}_{\mathrm{x}} \mathrm{O}_{40}{ }^{3-}(\mathrm{x}=0,3,6,12)$. Synthetic Metals. 2002;129(1):53-59. 